\title{
¿Es el lucro un elemento decisivo en la delimitación de las organizaciones cooperativas y de la Economía Social Solidaria? Un análisis comparado de las legislaciones de comienzo del siglo XXI
}

\author{
Pablo Guerra \\ Universidad de la República, Montevideo (Uruguay)
}

\section{Resumen}

Durante un tiempo considerable buena parte de la doctrina cooperativa señalaba que las cooperativas eran entidades sin fines de lucro. Algunas leyes, sobre todo de mediados del S. XX, recogían esa fórmula a la hora de definir la naturaleza de estas particulares empresas. En la actualidad, sin embargo, doctrina y legislaciones parecen abandonar dicha formulación. En este artículo ahondaremos en las razones de esta evolución y analizaremos cómo los textos legales más representativos que sobre la economía social y solidaria se han ido gestando en diferentes países de América en lo que va del S. XXI, han tratado la naturaleza de las empresas del sector solidario en relación con el lucro.

\section{Palabras clave}

Economía social y solidaria; lucro; cooperativas; legislación; doctrina cooperativa

Códigos JEL: K23, L21, L31, P13
IS THE PROFITS A CRUCIAL ELEMENT IN THE DELIMITATION OF COOPERATIVE AND SOCIAL AND SOLIDARITY ECONOMY ORGANIZATIONS? A COMPARATIVE OF THE LAWS OF THE BEGINNING OF CENTURY XXI ANALYSIS

\section{Abstract}

For a long time some cooperative doctrine defined the cooperatives as a non-profit corporation. Some laws, especially of mid-20th century, defined the nature of these particular organizations using this idea. Today, however, doctrine and legislation seem to leave such formulation. In this article we analize into the reasons for this evolution and will look at how the most representative SSE laws in different countries of South America have recognize the nature of the SSE sector in relation to the profits.

\section{Keywords}

Social and solidarity economy; non-profit; cooperative; laws; cooperative doctrine

JEL codes: K23, L21, L31, P13

Fecha de recepción del original: 17 de mayo de 2018; versión definitiva: 20 de diciembre de 2019.

\footnotetext{
Autor: Pablo Guerra, Profesor - Investigador, Área Socio Jurídica Facultad de Derecho, Universidad de la República (Montevideo - Uruguay) Colonia 1801, CP. 11.100, Montevideo - Uruguay

E-mail: profecosol@yahoo.com.ORCID ID: 0000-0002-2586-7175
} 


\section{¿Es el lucro un elemento decisivo en la delimitación de las organizaciones cooperativas y de la Economía Social Solidaria? Un análisis comparado de las legislaciones de comienzo del siglo XXI}

Pablo Guerra

Universidad de la República, Montevideo (Uruguay)

Introducción

Las cooperativas y otras organizaciones pertenecientes a la denominada economía social y solidaria se caracterizan por ser empresas asociativas ajustadas a una serie de principios y de valores. En el movimiento cooperativo esos principios y valores han ido evolucionando desde la constitución de la cooperativa Rochdale (Inglaterra, 1844) hasta la última formulación del Congreso de ACl celebrado en Manchester (Inglaterra, 1995). Dentro del movimiento de la economía social y solidaria, por su parte, no hay una sola formulación, aunque por el estudio de algunos de los documentos más fundamentales de las organizaciones más representativas se pueden mencionar aspectos como la supremacía de las personas sobre el capital, la participación democrática, el cuidado del medio ambiente, la justicia social, la equidad de género, etc.

Respecto a la forma en que se asignan y distribuyen los recursos obtenidos por estas organizaciones, no existió nunca una sola fórmula. Dentro de las denominadas organizaciones de primera generación (mutuas, asociaciones, cooperativas) la distinción fundamental fue históricamente entre aquellas que no redistribuyen eventuales excedentes entre sus socios (mutuas y asociaciones) y quienes sí podían hacerlo, al menos en parte (cooperativas). Dentro de las denominadas organizaciones de segunda generación (organizaciones de comercio justo, consumo responsable, finanzas éticas, empresas recuperadas, redes de pequeños productores, empresas sociales, etc.), mientras tanto, encontramos una mayor presencia y conexión entre la lógica empresarial alternativa por un lado y la lógica de la acción típica de las ONGs por otro. Es en este contexto que surge la diferenciación dentro del amplio abanico de la ESS, entre un polo más bien propio de las "entidades sin fines de lucro" y otro polo más aproximado a formas societales. Para agregar algo más de complejidad, en algunos países como España, resurge la categoría de "cooperativas sin fines de lucro" para hacer mención a aquellas que realizan algún tipo de servicio social contratadas por las administraciones públicas (Argudo Pérez, 2007; Montero, 2010).

De esta manera, en el sector solidario de nuestras economías advertimos la presencia de entidades que se aproximan más a la lógica del tercer sector ("organizaciones sin fines de lucro"), otras que se aproximan más a la lógica empresarial aunque con rasgos alternativos (aquí ubicamos a las cooperativas) y nuevos formatos más híbridos, que recogen aspectos de ambos, caso de las denominadas "empresas sociales", esto es, organizaciones que tienen una finalidad social que procuran mediante formatos empresariales. La irrupción en escena de las "cooperativas sin fines de lucro" por su parte, nos permite comprender que esta hibridación no solo es posible observarla en el campo del derecho mercantil, sino además en el campo del derecho cooperativo. Efectivamente, el hecho que algunas legislaciones (caso de la ley estatal de cooperativas de España de 1999) recurran a dicha calificación, significa que se evoluciona hacia formatos cooperativos con diferentes variantes respecto al uso de los excedentes, así como a su finalidad: la cooperativa puede tener como fin satisfacer la necesidad de sus socios, pero también puede ser su finalidad la utilidad pública o el bien común. En el derecho mercantil, la irrupción de formatos como los de "empresas b" (denominadas originalmente "Bcorp" en EUA) muestran el mismo proceso de apertura hacia formatos híbridos que contemplan la finalidad social de estas empresas sin perjuicio de su finalidad también económica.

Una de las hipótesis en este artículo es que parte del cooperativismo ha manejado históricamente el asunto de la finalidad de lucro de una manera muy limitada, lo que ha conducido a un mal uso doctrinario e incluso jurídico que está comenzando a revertirse desde hace algunos años. A nivel doctrinario, por mucho tiempo se esgrimió que las cooperativas eran organizaciones que no perseguían fines de lucro. Se hizo, como veremos luego, fundamentalmente con el propósito de distinguirlas de las empresas capitalistas (y por ende del régimen de tributación de éstas), pero confundiendo nociones como 
lucro, ganancias, excedentes y utilidades ${ }^{1}$. A nivel jurídico, esas expresiones dieron lugar a legislaciones cooperativas que desde mediados del S. XX plasmaron dicha formulación y que como también veremos más adelante, comienzan a perder terreno en las últimas generaciones de leyes relacionadas a la ESS.

Las dificultades conceptuales en torno al lucro

La manida definición de las cooperativas como organizaciones o empresas que no persiguen fines de lucro es sumamente imprecisa, además de equivocada y cargada de preconceptos ideológicos. Es imprecisa pues no se sabe exactamente a qué se refiere con el lucro. ¿Es acaso el lucro sinónimo de ganancia, sinónimo de excedentes, de utilidades o de beneficios? Claramente una empresa cooperativa, al igual que todas las empresas que con sus particularidades forman parte del mercado, debe procurar ciertos resultados económicos favorables. Incluso llegar a un cierto "punto de equilibrio" puede ser una aspiración razonable en el corto plazo, pero sin excedentes que permitan por ejemplo reinversiones, la posibilidad de sobrevivir a mediano plazo son muy bajas. Eso significa que en algún momento las empresas cooperativas para ser sustentables necesitan contar con mayores ingresos que egresos. Hasta aquí no tiene sentido entonces equiparar al lucro con esos necesarios excedentes. Demos un paso más. Hay quien pudiera pensar que en realidad lo que está en discusión no es ese margen positivo que se necesita para las necesarias reinversiones que contemplen la posibilidad de seguir compitiendo en el mercado. Se dirá entonces que lo que no se persigue es obtener resultados más allá de ese corte. $O$ sea, la cooperativa no debería obtener ganancias más allá de un monto $x$ destinado a fondos de reserva y reinversión. Esto podría ser cierto para algunos casos, sin embargo, entramos al terreno filosófico de la justa ganancia, temática que poco aporta en términos estrictamente operativos. Pero incluso para otros casos, topear las eventuales utilidades/ganancias parecería ser injusto. Supongamos que una cooperativa de trabajadores que se constituye para mejorar los ingresos económicos de sus familias logra una buena productividad. ¿Podríamos considerar en ese caso que las eventuales utilidades que superen el excedente para reinversión no deberían ir a manos de los creadores de ese valor? No parece razonable. En definitiva, la fórmula que estamos analizando es sumamente imprecisa pues nos deja sin elementos para definir a qué se refiere exactamente con el lucro. Podría definirse en el texto legal, pero eso no lo volvería una solución universal. Véase, por ejemplo, que para Hagen la diferencia entre utilidades y excedentes es que las primeras se generan en actividades de la cooperativa con no socios, en tanto los excedentes "deriva de las operaciones con los asociados"

\footnotetext{
${ }^{1}$ Brugarola reconocía en 1961 "pareceres contradictorios" en la doctrina cooperativa: "por una parte se afirma que la cooperativa no busca ningún lucro; por otra, se afirma que la cooperativa pretende un beneficio, una ganancia" (Brugarola, 1961: 44).
}

(Hagen, 2013: 39). A nuestra manera de ver esa es una definición posible entre varias ${ }^{2}$. Pero incluso así, en algunos casos esa distinción (las "utilidades" no se reparten; los excedentes sí), útil para ciertas cooperativas de usuarios, no tendría mayor aplicabilidad, como por ejemplo en cooperativas de producción donde sus trabajadores venden lo producido a terceros. Pero además de lo impreciso que puede llegar a ser la voz "lucro" es impreciso el concepto de"finalidad" de lucro o más aún "ánimo de lucro" (animus lucrandi). Llegado a cierto punto algunos podrían decir que las cooperativas no "persiguen un fin de lucro" pero sí necesitan de cierto lucro. Resulta algo paradójico, tanto como decir que las cooperativas pueden lucrar, aunque no sea ese su propósito. En la misma línea, alguien más podría insistir que a diferencia de las empresas capitalistas que buscan "maximizar el lucro" las cooperativas más bien buscan un lucro relacionado al propósito de la cooperativa. Pero en definitiva entramos en un terreno lleno de subjetividades. Coincidimos con Hagen en que más allá de si el lucro es un fin o un medio para otro fin, se trata de una fórmula llena de ambigüedades, falta de "criterios tangibles y verificables" (Hagen, 2013: 39).

Decimos por su parte que es una fórmula equivocada, pues las cooperativas sí pueden repartir excedentes entre su masa social en caso de que existan. Casi todas las legislaciones cooperativas reglamentan el porcentaje que puede ser distribuido a prorrata entre sus socios.

Finalmente está cargada de prejuicios, pues claramente parece haber en el término "lucro" una connotación negativa que no tienen algunos de sus sinónimos o términos parecidos (caso de utilidades, beneficios, ganancia o excedentes).

Coincidimos en tal sentido con Razeto, para quien las cooperativas son empresas que se proponen obtener en el ciclo económico un resultado positivo que compense al factor organizador (caso del trabajo en las cooperativas de producción, o del factor $C$ en el resto de las cooperativas). O sea, hay en las empresas cooperativas un propósito de obtener una ganancia. Lo que las distingue de las otras empresas es cómo las reparte. Crítico a quienes sostienen que en los casos de cooperativas cerradas a la operativa con sus socios no se puede hablar de ganancias sino de sobre precios al socio, Razeto argumenta que "toda cooperativa ... establece no solo relaciones comerciales con sus socios, sino con diferentes otros sujetos económicos, sea el personal rentado que aporta fuerza laboral, tecnología administración, etc., sean los abastecedores de medios materiales, insumos y mercaderías que la cooperativa transforma y vende a sus socios. Las ganancias como empresa existirán [...]" (Razeto, 1991: 49). Ejemplificando, aunque una cooperativa de consumo logre vender a sus socios al precio exacto y no se generaran excedentes contables, la ganancia estaría en el hecho de haber recibido productos por debajo del precio de mercado, de mejor calidad, etc. Concluyendo, Razeto sostiene que la principal identidad de una cooperativa no debe pasar por una "discutible distinción entre ganancia y lucro" ni en el hecho de que no persiga o realice una utilidad. Dando un

\footnotetext{
2 Razeto, por ejemplo propone otras. Es así que distingue dentro de los denominados "beneficios" a la ganancia (diferencia entre ingresos y costos), las "utilidades" (conjunto de beneficios obtenidos por los sócios, sean monetarios o no monetarios), y "excedentes" (diferencia entre ingresos y pagos a terceros, incluyendo reservas) (Razeto, 1991: 51).
} 
nuevo paso señala que tampoco es decisivo definir sus fines: "la diferencia fundamental respecto a la empresa capitalista (es que) la cooperación actúa siempre en beneficio de categorías económicas (y sociales) distintas del capital..." (Razeto, 1991:51).

Reforzando estas ideas, Cano López señala que desde los años 50 la doctrina mercantil comienza a abandonar la noción de fines de lucro como el aspecto que caracterizaría a la actividad empresarial. ¿Razones? Su respuesta es categórica:"por la extrema vaguedad del concepto [...] y la consiguiente inseguridad que provoca" (Cano López, 2002: 149).

Teniendo en cuenta lo anterior, es que nos parece más adecuado evitar la fórmula en discusión y poner el acento en lo que realmente importa: cómo distribuyen sus eventuales excedentes las empresas del sector solidario de la economía. Las soluciones a esta problemática es bastante sencilla: en el caso de las mutuales y asociaciones, no hay distribución de excedentes; en el caso de las cooperativas puede haberlo al menos hasta una determinada proporción (véase el tercer principio sobre participación económica de los socios); en el caso de algunas cooperativas con rango especial (caso de las cooperativas sociales en Uruguay o de las cooperativas sin fines de lucro en España) tampoco se permite la distribución de excedentes entre los socios. Dicho de otra manera, la forma en cómo se distribuyen las eventuales utilidades diferencia al conjunto de empresas del sector solidario con respecto a las empresas del sector capitalista. En este último prima la distribución a los propietarios de capital (accionistas) en relación a la inversión realizada (capital aportado).

El tratamiento clásico y el tratamiento contemporáneo en las cooperativas

Desde nuestro punto de vista denominaremos tratamiento clásico para el caso latinoamericano, a aquella formulación que ve a las cooperativas como organizaciones que no persiguen fines de lucro. Notoriamente son organizaciones que pueden distribuir entre su masa social eventuales excedentes, pero éstos son considerados "un exceso en la previsión de costos" antes que una "ganancia" (Orecchia, 2004: 28). El punto de partida de este enfoque es que la finalidad de las cooperativas es "resolver una necesidad común de sus asociados", antes que obtener una ganancia (Cracogna, 2004: 168). Diferentes legislaciones, sobre todo desde los años 60s, han adoptado este modelo. Para el caso latinoamericano debemos destacar por su importancia, a la Ley 5764 de Brasil (1971). En su Art. 3 se expresa:

"Celebran contrato de sociedade cooperativa as pessoas que reciprocamente se obrigan a contribuir con bens o servicos para o exercício de una atividade economica, de proveito comun, sem objetivo de lucro" (Brasil, 1971, Art. 3) (cursivas nuestras).
Otras legislaciones en la región siguieron este criterio. Por ejemplo, la Ley 6756 de Costa Rica (1982), en su Art. 2 establece:

"Las cooperativas son asociaciones voluntarias de personas y no de capitales, con plena personalidad jurídica, de duración indefinida y de responsabilidad limitada, en las que los individuos se organizan democráticamente a fin de satisfacer sus necesidades y promover su mejoramiento económico y social, como un medio de superar su condición humana y su formación individual, y en las cuales el motivo del trabajo y de la producción, de la distribución y del consumo, es el servicio y no el lucro (Costa Rica, 1982: Art. 2).

Antes en el tiempo, la Ley 127/64 de República Dominicana establece en su Art. 1:

"Son cooperativas las sociedades de personas naturales y jurídicas sin fines de lucro que reúnan las siguientes condiciones [...]" (República Dominicana, 1964).

Muy sintomático fue el caso chileno. La original ley de 1960 (DFL 326) no incluía el término lucro en la definición del objeto legislado. Este término sí se agrega a la definición de la cooperativa en el Decreto 502/1978 (plena dictadura), para volver a desaparecer en 2002, cuando se regresa a la redacción original. Decía el texto legal de 1978 en su Art. 1:

"Para los fines de la presente ley son cooperativas las instituciones sin fines de lucro que, teniendo por objeto la ayuda mutua, se rigen por sus disposiciones y presentan las características fundamentales siguientes [...]" (Chile, 1978) (subrayado nuestro).

Esta tendencia también tuvo presencia en las legislaciones europeas. El Código Cooperativo de Portugal de 1980, por ejemplo, definió a las cooperativas de la siguiente manera en su Art. 2:

"As cooperativas são pessoas colectivas, de livre constituição, de capital e composição variáveis, que visam através da cooperação e entreajuda dos seus membros e na observância dos princípios cooperativos, a satisfação, sem fins lucrativos, das necessidades económicas, sociais ou culturais destes, podendo ainda, a título complementar, realizar operações com terceiros (Portugal, 1980: 3).

Es de destacar que futuros cambios a esta legislación no afectaron la redacción original.

Por fuera de esta definición clásica que como dijimos se caracteriza por incluir el concepto de ausencia de finalidad de lucro, tenemos el modelo que opta por evitar su inclusión en los textos legales. Este modelo, al que llamaremos contemporáneo, adquiere fuerza luego de la definición de cooperativa dada por la Il Asamblea General de la ACl (Manchester, 1995) en el marco de la nueva Declaración sobre Identidad Cooperativa. También está presente en otros dos textos fundamentales: las Directrices de las Naciones Unidas encaminadas a crear un entorno propicio para el desarrollo de las cooperativas del año 2001 (Directrices de las 
Naciones Unidas) y la Recomendación n 193 sobre la promoción de las cooperativas de la Organización Internacional del Trabajo del año $2002^{3}$.

Es de destacar que la Ley Marco para las Cooperativas de América Latina asume esa definición que luego -como veremosse plasma en algunos textos legislativos nacionales. Antes, incluso, la ausencia de toda referencia al lucro se expresa en legislaciones como es el caso, entre otras, de la ley de cooperativas n²0.337 de Argentina (1973). El Art 2 expresa:

"Las cooperativas son entidades fundadas en el esfuerzo propio y la ayuda mutua para organizar y prestar servicios, que reúnen los siguientes caracteres: [...]" (Argentina, 1973: Art. 2).

Entre los caracteres no menciona la no finalidad de lucro. De manera acertada (a nuestro criterio) incluye criterios específicos en lo que respecta a la distribución de excedentes, así como a la irrepartibilidad de los activos y reservas, pero evitando el uso de un término que como veremos luego, genera más confusión que claridad. En el MERCOSUR, solo Uruguay siguió esta línea. En las diversas normas que precedieron a la actual Ley General de Cooperativas (LGC) de 2008, no se menciona al lucro en las definiciones adoptadas, aspecto que continúa la LGC. Dice su Art. 4:

"Las cooperativas son asociaciones autónomas de personas que se unen voluntariamente sobre la base del esfuerzo propio y la ayuda mutua, para satisfacer sus necesidades económicas, sociales y culturales comunes, por medio de una empresa de propiedad conjunta y democráticamente gestionada" (Uruguay, 1998: Art. 4).

Como se puede notar, se trata de una definición al estilo de las expresadas en los textos más representativos de la $\mathrm{ACl}$, caso de la ya citada "Declaración sobre la Identidad Cooperativa" de 1995 (ACl, 1995).

El tratamiento del lucro en las nuevas tendencias legislativas

A los efectos de este artículo, consideraremos el tratamiento que las definiciones legislativas han dado a la temática del lucro. Para ello, nos concentraremos en las legislaciones que sobre ESS han venido desarrollándose en la región iberoamericana, tomando como hito inicial en la periodización, la ley 454 de

\footnotetext{
3 Incluso antes, en la Recomendación 127 de la OIT, se partía de una definición de corte contemporáneo: "una asociación de personas que se agrupan voluntariamente para lograr un objetivo común mediante la formación de una empresa controlada democráticamente, que aportan una cuota equitativa del capital que se requiere y aceptan una justa parte en los riesgos y beneficios, y en cuyo funcionamiento los socios participan activamente" (OIT, 1966: 12).
}

Colombia (1998), primera en incorporar con criterios actualizados la denominación "economía solidaria" en un texto legislativo ${ }^{4}$. En cuanto al recorte operativo, consideramos ley de ESS cualquier texto legal que incorpore una definición del sector de la ESS y que incorpore explícitamente los términos "economía social", "economía solidaria" o ambos. También sumaremos algunos proyectos de ley actualmente a estudio por parte de los legisladores.

Teniendo en cuenta la periodización 1998-2018 (últimos 20 años) y la definición operativa antes señalado, las normas a revisar serán (orden alfabético):

\begin{tabular}{|l|l|}
\hline \multicolumn{1}{|c|}{ País } & \multicolumn{1}{c|}{ Leyes y Proyectos } \\
\hline Argentina & $\begin{array}{l}\text { Provincia de Entre Rios (2012), Provincia de Mendoza } \\
\text { (2012), Provincia de Buenos Aires (2014). Instituto } \\
\text { Nacional de Economía Social (INAES, 2013). }\end{array}$ \\
\hline Brasil & $\begin{array}{l}\text { Leyes Municipales y Estadules (18 estados). Proyecto } \\
\text { de Ley 4865/2012 (actualmente en estudio Cámara de } \\
\text { Diputados) }\end{array}$ \\
\hline Colombia & Ley 454/1998 \\
\hline Ecuador & Ley Orgánica de la Economía Popular y Solidaria (2011) \\
\hline Mexico & Ley de la Economía Social y Solidaria (2011) \\
\hline $\begin{array}{l}\text { República } \\
\text { Dominicana }\end{array}$ & Proyecto de Ley ESS (2010) \\
\hline Uruguay & Anteproyecto Ley ESS (2015) \\
\hline
\end{tabular}

A los efectos comparativos con la península ibérica, también incluiremos los textos legislativos de España y Portugal, a saber:

\begin{tabular}{|l|l|}
\hline País & Ley \\
\hline España & Ley 05/2011, Economía Social \\
\hline Portugal & Ley 30/2013, Ley de bases de la economía social (LBES) \\
\hline
\end{tabular}

(a) Argentina

Para el caso de Argentina revisaremos las leyes sobre ESS adoptadas en las Provincias así como el proyecto de ley que INAES elevó al Congreso Nacional.

La Ley de Promoción de la Economía Social y Solidaria 8435 de la Provincia de Mendoza introduce una interesante novedad en el estilo de redacción:

"A los fines de la presente Ley se entiende por Economía Social y Solidaria (E.S. y S.) al conjunto de recursos y actividades, y grupos, instituciones y organizaciones, que operan

\footnotetext{
${ }^{4}$ Como explicamos en Guerra (2013), la primera ley que incopora la voz "economía social" es de Honduras (decreto ley 193/1985). Sin embargo, para esta ocasión hemos preferido comenzar la periodización con la ley colombiana habida cuenta que la hondureña se focaliza solamente en el segmento autogestionario, antes que en un sector más amplio.
} 
según principios de solidaridad, cooperación y autoridad legítima, en la incorporación y disposición de recursos para la realización de actividades de producción, distribución, circulación, financiamiento y consumo digno y responsable; cuyo sentido no es el lucro sin límites sino la resolución de las necesidades de los trabajadores, sus familias y comunidades, y del medio ambiente; para lograr una sociedad más justa, inclusiva e igualitaria" (Mendoza, 2012: Art. 2).

Como se puede observar, se trata de una definición muy cargada de conceptos que refieren a una determinada ética económica. Sobresale a los efectos de este artículo, que no se mencione el concepto de "empresa" en la definición, aunque sí otro conjunto de actores de la economía, como si la empresa fuera en sí misma una categoría capitalista. Pero por encima de todo, es de destacar que se refiere al lucro de una manera muy original. Señala que el "sentido" "no es el lucro sin límites" "sino la resolución de las necesidades de los trabajadores, sus familias y comunidades, y del medio ambiente" ${ }^{\prime \prime}$. Más allá de lo extraño que resulta el término "sentido" en un texto legal, lo que procura señalar el legislador es que las organizaciones de la ESS pueden recibir un lucro, pero solo hasta cierto punto. Una fórmula comprensible en el marco de cierta ética económica, pero insuficiente para una solución legal: ¿cuál es el límite? ¿10\%, 100\%?; ¿respecto a qué se pone límite? ¿a las ganancias más allá del pago a factores externos o además internos? ¿al eventual reparto de utilidades entre los socios? Las preguntas se suceden. Nótese por su parte, que una corporación internacional puede argumentar que no persigue lucros sin límites, sino que ajustados a una determinada planificación estratégica.

Una redacción parecida es la que aparece en el texto legal de la Provincia de Entre Ríos:

"A los efectos de esta ley se entenderá por Economía Social al conjunto de actividades orientadas a la producción de bienes y servicios, a su distribución, circulación, y consumo de modo asociativo o comunitario, realizadas por personas y/o entidades que están organizadas de modo económicamente equitativo, y que operan regidas por los principios de participación democrática en la toma de decisiones, autonomía de la gestión, la primacía del ser humano y del fin social sobre el capital, y como productora y sostén para la soberanía alimentaria. Las prácticas de estos actores se circunscriben en una conceptualización diferente de los factores de la producción, donde la solidaridad es el pilar para su funcionamiento, y su sentido no es el del lucro sin límites, sino la resolución de las necesidades de los trabajadores, sus familias y comunidades" (Entre Ríos, 2012: Art. 3).

Como se puede observar, se trata de una redacción compleja y con muchas aristas teóricas que a veces no resultan eficientes desde el punto estrictamente legislativo. Por ejemplo, ¿qué significa estar organizado de modo económicamente equitativo? ¿se trata del mismo ingreso por misma tarea? ¿mismo ingreso a pesar de diferentes tareas? ¿la definición de un piso y un techo en las retribuciones? ¿O más bien se trata de equidad de género? ¿en la plantilla de trabajadores o en los cargos directivos? En fin, las preguntas y las respuestas pueden ser múltiples. También podría resultar exagerado mencionar aspectos de teoría de factores en una ley: si bien el texto pretende señalar que la solidaridad económica es un factor determinante, se podría haber intentado una redacción más acorde a un texto legislativo. Finalmente, recurre a la misma redacción que la ley mendocina en lo que respecta al lucro.

La ley de promoción y desarrollo de la ESS en la Provincia de Buenos Aires (2014) recurre a una definición algo diferente:

\begin{abstract}
"A los efectos de esta Ley se entenderá por Economía Social y Solidaria a la estrategia de desarrollo basada en la promoción y fomento de relaciones económicas con perspectiva de derechos humanos, en las que debe primar la dignidad de las personas. Comprende al conjunto de recursos y actividades, de personas, instituciones y organizaciones, que operan según principios de solidaridad, cooperación y autoridad legítima, la apropiación y disposición de recursos, en la realización de actividades de producción, distribución, circulación, financiamiento y consumo digno y responsable, cuyo sentido es la resolución de las necesidades de los trabajadores, sus familias y comunidades, y del medio ambiente; para lograr una sociedad más justa, inclusiva e igualitaria (Buenos Aires, 2014: Art. 3).
\end{abstract}

Como se puede observar, esta redacción incluye elementos de las anteriores, pero evita la mención al lucro. Es cierto que se trata de una definición muy amplia que puede dar lugar a la entrada de múltiples actores económicos. Pero esa limitación se subsana con el Art. 4 donde se mencionan cuáles son los sujetos de la ley, desde grupos asociativos vulnerables hasta cooperativas y mutuales.

El anteproyecto de ley nacional de promoción de la economía popular, social y solidaria, por su lado, define de la siguiente manera a la ESS:

"A los efectos de esta ley se denomina Economía Popular, Social y Solidaria al conjunto de las actividades económicas de producción, distribución, comercialización, financiamiento y consumo de bienes y servicios que, de conformidad con los principios enunciados en el artículo $3^{\circ} \mathrm{y}$ basadas en relaciones de solidaridad, reciprocidad y cooperación, estén dirigidas a satisfacer necesidades y generar ingresos, privilegiando el trabajo humano y el desarrollo sustentable sobre la acumulación de capital" (Argentina, 2013: Art. 2).

Esta definición opta por no mencionar al lucro como aspecto distintivo. Muestra cierta apertura a la diversidad de propósitos cuando se menciona que están "dirigidas a satisfacer" tanto necesidades como generación de ingresos. Es de destacar que el Art. 5 de este anteproyecto crea la figura de los "Grupos Asociativos de la Economía Social" donde explícitamente menciona que pueden tener "actividad lucrativa".

\footnotetext{
${ }^{5}$ Curiosamente el Decreto Reglamentario de la Ley quita esa mención al lucro, manteniéndo inalterado el resto de la definición.
} 
(b) Brasil

Luego de algunos años de puesta en marcha de las primeras políticas públicas para el fomento de la economía solidaria en Brasil, fue presentado en 2012 un proyecto de Ley que al momento de escribir este artículo ya había sido tratado por el Senado, faltando el debate en la Cámara de Diputados. En el proyecto, se define a la economía solidaria de la siguiente manera:

"Considerase compatível com os princípios da Economia Solidária as atividades de organização da produção e da comercialização de bens e de serviços, da distribuição, do consumo e do crédito, tendo por base os princípios da autogestão, da cooperação e da solidariedade, a gestão democrática e participativa, a distribuição equitativa das riquezas produzidas coletivamente, o desenvolvimento local, regional e territorial integrado e sustentável, o respeito aos ecossistemas, a preservação do meio ambiente, a valorização do ser humano, do trabalho, da cultura, com o estabelecimento de relações igualitárias entre diferentes" (Brasil, 2012).

Se trata de una definición com muchos componentes de ética económica pero escasos elementos decisivos para el recorte concreto de los sujetos de la economía solidaria. En lo que refiere a nuestro propósito, no hay mención alguna al tema de las ganancias o lucro (como sí sucede con su legislación cooperativa, que como hemos visto es representativa de la tradición clásica). Enla sección II establece criterios de distribución de los ingresos y se establece que las organizaciones deben tener naturaleza económica como razón primordial de su existencia.

Antes, muchas ciudades y Estados habían legislado en economía solidaria. A manera de ejemplo, Río de Janeiro publicó su ley en 2008. Aunque no presente una definición, en su Art. 3 detalla las características que deben tener sus emprendimientos. No figura ninguna referencia a la ausencia de lucro (Río de Janeiro, 2008) aunque prescribe la distribución de resultados al interior de las organizaciones a fin de velar por su sustentabilidad.

A nivel estatal, uno de los Estados más abanderados con la economía solidaria ha sido Rio Grande do Sul. Su ley de 2010 establece:

"O setor da economia popular solidária é formado por empresas, cooperativas, redes e empreendimentos de autogestão preenchendo, cumulativamente, os seguintes requisitos:

I - que sejam organizados sob os princípios da cooperação, da solidariedade, da autogestão, da sustentabilidade econômica e ambiental e da valorização do ser humano e do trabalho; II - cujo objetivo, patrimônio e resultados obtidos sejam revertidos para melhoria, sustentabilidade e distribuição de renda entre seus associados;

III - que tenham por instância máxima de deliberação, para todos os fins, assembleia periódica de seus associados, onde todos tenham direito a voz e a voto, e por instâncias intermediárias aquelas que garantam a participação direta dos associados de acordo com as características de cada empreendimento; \}

IV - que adotem sistemas de prestação de contas detalhadas de acordo com as necessidades e interesses dos associados, em especial, do Fundo de Assistência, Educacional e Social; V - cujos sócios sejam seus trabalhadores, produtores, usuários ou gestores;

VI - cuja participação de trabalhadores não associados seja limitada a $10 \%$ (dez por cento) dos primeiros 30 (trinta) associados mais $1 \%$ (um por cento) do número que exceder a 30 (trinta), limitado ao máximo de 500 (quinhentos) associados;

e VII - cuja maior remuneração não exceda a 6 (seis) vezes a menor remuneração (RS, 2010: Art. 2)

Se trata de una redacción lograda que no incluye la fórmula clásica del lucro. Por el contrario, establece que los resultados económicos pueden ser distribuidos al interior de la organización o entre los socios trabajadores.

(c) Colombia

Colombia ha sido pionero en legislar sobre el sector solidario de nuestras economías. La ley 454 de 1998 incorpora por primera vez en un texto legal, la definición de la economía solidaria:

"Para efectos de la presente ley denomínese Economía Solidaria al sistema socioeconómico, cultural y ambiental conformado por el conjunto de fuerzas sociales organizadas en formas asociativas identificadas por prácticas autogestionarias solidarias, democráticas y humanistas, sin ánimo de lucro para el desarrollo integral del ser humano como sujeto, actor y fin de la economía" (Colombia, 1998: Art. 2).

Se trata de una definición que pretende evitar el economicismo al incorporar las dimensiones sociales, culturales y ambientales. Como se observa, es en parte heredera de la tradición clásica al señalar como característica de las formas asociativas pertenecientes al sector, su carácter "sin ánimo de lucro".

(d) Ecuador

La Constitución de Ecuador de 2008 explícitamente señala la importancia del sector solidario de la economía y mandató al Estado a legislar sobre estos asuntos. Dice la Constitución en su Art. 283: 
"El sistema económico se integrará por las formas de organización económica pública, privada, mixta, popular y solidaria, y las demás que la Constitución determine. La economía popular y solidaria se regulará de acuerdo con la ley e incluirá a los sectores cooperativistas, asociativos y comunitarios" (Ecuador, 2008: Art. 283).

En ese marco el Ministerio de la Inclusión Económica y Social (MIES) tuvo a su cargo el trabajo de elaboración de un proyecto de ley donde intervinieron numerosos actores sociales. El resultado fue la Ley Orgánica de la Economía Popular y Solidaria y del Sector Financiero Popular y Solidario de 2011, que define así al sector:

"Para efectos de la presente Ley, se entiende por Economía Popular y Solidaria a la forma de organización económica, donde sus integrantes, individual o colectivamente, organizan y desarrollan procesos de producción, intercambio, comercialización, financiamiento y consumo de bienes y servicios, para satisfacer necesidades y generar ingresos, basadas en relaciones de solidaridad, cooperación y reciprocidad, privilegiando al trabajo y al ser humano como sujeto y fin de su actividad, orientada al buen vivir, en armonía con la naturaleza, por sobre la apropiación, el lucro y la acumulación de capital" (Ecuador, 2011: Art. 1).

Si bien lo más llamativo de esta redacción es que incluya sujetos individuales, nos detendremos especialmente en la inclusión del término lucro. La Ley de Ecuador agrega una nota de originalidad al evitar la fórmula clásica, pero al mismo tiempo incorpora la voz "lucro" para anteponerla al concepto del "buen vivir". En buen romance, el legislador pretendió poner acento en el móvil que debe guiar a la EPS ("orientada al buen vivir, en armonía con la naturaleza) por sobre otros móviles como la "apropiación, el lucro y la acumulación de capital". Pero estos otros móviles no fueron prohibidos, sino llevados a un segundo orden (en ese sentido se escogió el nexo"por sobre").

(e) México

\section{El Art. 25 de la Constitución de México establece que}

"Al desarrollo económico nacional concurrirán, con responsabilidad social, el sector público, el sector social y el sector privado, sin menoscabo de otras formas de actividad económica que contribuyan al desarrollo de la Nación /.../ Bajo criterios de equidad social y productividad se apoyará e impulsará a las empresas en los sectores social y privado de la economía, sujetándolos a las modalidades que dicte el interés público y al uso, en beneficio general, de los recursos productivos, cuidando su conservación y el medio ambiente" (México, 2011).

Bajo ese marco constitucional, se aprobó el 23 de noviembre de 2011 la legislación más novel de economía social y solidaria en la región, esto es, la Ley General sobre Economía Social y Solidaria. Esta Ley opta por evitar una definición del sector, aunque en las consideraciones de la norma se señala que la ESS "responde a las necesidades de los grupos sociales de organizarse para satisfacer sus necesidades materiales comunes"(México, 2011:2). El término "lucro" no aparece tampoco en el listado de orientaciones que deben seguir los diferentes actores enumerados por la Ley.

\section{(f) República Dominicana}

En 2010 un grupo de organizaciones sociales y cooperativas elaboraron un"proyecto de ley del sector de la economía solidaria" que fue elevado a la Cámara de Diputados en 2011. El Art. 222 de su Constitución por su parte

"reconoce el aporte de las iniciativas económicas populares" citando el caso de "las cooperativas /.../ y otras formas de asociación comunitaria para el trabajo, la producción, el ahorro y el consumo" (Dominicana, 2010: Art. 222).

El proyecto defina de la siguiente manera a la ESS:

"Sistema socioeconómico, cultural y ambiental, desarrollado de forma asociativa por trabajadores y trabajadoras, a través de prácticas solidarias y participativas, para el bienvivir, el desarrollo integral del ser humano como fin de la economía, por lo tanto, no tiene fines lucrativos [...]" (en Guerra y Reyes, 2014: 116).

Como podemos observar, este texto presenta una redacción más propia del enfoque clásico al exponer que las formas asociativas de la ESS persiguen el bienvivir y el desarrollo integral del ser humano, concluyendo (a nuestra manera de ver de forma equivocada) que, "por lo tanto, no tiene fines lucrativos".

(g) Uruguay

Entre los años 2012 y 2015 hubo una serie de eventos académicos y gremiales que tuvieron como propósito instalar el debate sobre la pertinencia de una ley de economía solidaria para el país. Fruto de ese trabajo, el INACOOP constituye una comisión que redactó un anteproyecto de ley que ingresa al Parlamento en 2018. La definición dada a la ESS por este texto es la siguiente:

"Se entiende por Economía Social y Solidaria al sistema socioeconómico, cultural y ambiental, conformado por el conjunto de organizaciones y redes que desarrollan fines colectivos o sociales, caracterizado por las prácticas solidarias, asociativas, cooperativas y de ayuda mutua, la participación democrática en la toma de decisiones, la autonomía de la gestión, la primacía del ser humano y del bien común sobre el 
capital, la equidad social y de género, el respeto a la naturaleza, la diversidad cultural y el desarrollo local, con el objetivo de satisfacer las necesidades de sus integrantes o de la comunidad en procura del desarrollo humano y la democratización de la economía a partir de la producción de bienes y servicios, su distribución, circulación, comercialización, financiamiento y consumo justo y responsable" (Comisión de Trabajo por Ley de ESS, 2015).

Como se puede observar, es una redacción que incorpora elementos de otras legislaciones, tiene cierta densidad doctrinaria y cuando se refiere a los objetivos de los sujetos de la ESS, mantiene una descripción de identidad en términos positivos. Por ende, no menciona al lucro.

(h) España y Portugal

La Ley 5/2011 fue fruto de varios acuerdos políticos a partir de algunas elaboraciones provenientes del campo académico. Una vez plasmada en un texto normativo, tuvo influencias en otros procesos en la región latinoamericana. Define a la "economía social" de la siguiente manera:

"conjunto de las actividades económicas y empresariales, que en el ámbito privado llevan a cabo aquellas entidades que, de conformidad con los principios recogidos en el artículo 4, persiguen bien el interés colectivo de sus integrantes, bien el interés general económico o social, o ambos" (España, 2011: Art. 2).

La definición precisa los objetivos que persiguen las entidades de la economía social y como se puede observar no menciona al lucro, distinguiendo aquellas entidades que se conforman para perseguir el interés colectivo e sus integrantes (p.e. Una cooperativa), aquellas que persiguen un interés más general (p.e. Una asociación) o ambos. Se presume que las primeras pueden distribuir las utilidades entre sus socios y las segundas al fin social objeto de la entidad.

Dos años más tarde llegaría el turno a Portugal por medio de la Ley 30/2013 sobre "Bases de la Economía Social". Su Art. 2 incorpora la siguiente definición:

“Entendese por economia social o conjunto das atividades económico-sociais, livremente levadas a cabo pelas entidades referidas no artigo $4 .^{\circ}$ da presente lei" señalando a continuación que "As atividades previstas no n. ${ }^{\circ} 1$ têm por finalidade prosseguir o interesse geral da sociedade, quer diretamente quer através da prossecução dos interesses dos seus membros, utilizadores e beneficiários, quando socialmente relevantes (Portugal, 2013: Art. 2).

Como se puede observar, siguiendo la tendencia de España, distingue dentro de la economía social a entidades que persiguen un interés general de la sociedad y aquellas que persiguen el interés de sus miembros, usuarios o beneficiarios. En este último caso, la Ley establece la legitimidad de distribuir los excedentes conforme la propia naturaleza de la entidad.

\section{Conclusiones}

Creemos que algunas de las tendencias más generales que han primado en los últimos años en materia del derecho cooperativo y del accionar concreto de sus actores, han estado incidiendo en la tendencia al abandono del enfoque que en este artículo denominamos clásico. Una de esas tendencias, es el pasaje de una primera oleada de legislaciones más preocupada en marcar las diferencias con las empresas basadas en el capital (sociedades comerciales) hacia una oleada de legislaciones que se propusieron encontrar puntos en común entre ambos formatos. Dice Hagen en tal sentido, que las primeras leyes

"surgieron como consecuencia de la percepción de que la legislación sobre sociedades de capital era inadecuada para regular las cooperativas $y$, por lo tanto, diferenciaron a las cooperativas de las sociedades de capital", en tanto "en los comienzos de los años setenta se consolida una tendencia a la alineación de las cooperativas con las sociedades comerciales a través de las políticas y de la legislación..." (Hagen, 2013: 10-11)

Una primera posibilidad entonces es entender la ausencia de la anotación sobre el fin de lucro, como parte de una tendencia mayor de las legislaciones por encontrar mayores vasos comunicantes entre las sociedades mercantiles y las sociedades cooperativas. Una segunda posibilidad, sin embargo, es entender la necesidad de diferenciar ambos tipos de empresas sobre bases teóricas más consistentes. En lo particular nos afiliamos a esta tesitura.

Otro de los cambios visibles en el plural sector solidario de nuestras economías es el pasaje de las cooperativas centradas en sus propósitos económicos para satisfacer necesidades de sus integrantes, a entidades cooperativas o empresas solidarias centradas en propósitos más sociales y con impacto más allá del núcleo constitutivo de asociados. Para algunos, el concepto de "empresa social" resume ese propósito de incidir en objetivos de mayor alcance social respecto al núcleo de asociados. Aun así, nótese que muchas de esas empresas sociales que se constituyeron para perseguir un objetivo social amplio, han recurrido a los tradicionales formatos cooperativos. Otras, mientras tanto, han emigrado a nuevos formatos cooperativos (p.e. Las cooperativas sociales italianas). Una tercera variante son las legislaciones que crean nuevos instrumentos (caso de la ley británica sobre empresas de interés comunitario). Desde este punto de vista, las nuevas tendencias legislativas en ESS lo que buscan al prescindir del concepto "fines de lucro" es poder incluir bajo un mismo sector y una misma legislación, organizaciones que tienen permitido el reparto de utilidades y otras que se constituyen para perseguir un objetivo social y por lo tanto las eventuales utilidades deben utilizarse para ese cometido. 
En América Latina el enfoque clásico ha tenido una fuerte ascendencia en la legislación cooperativa y también en algunos textos de doctrina cooperativa, sobre todo en la segunda mitad del S. XX. En lo que respecta a la nueva oleada de legislaciones en ESS de los últimos veinte años, son tres las tendencias en el continente: (a) textos que siguen incorporando resabios de aquella fórmula tan errante; (b) textos que apuestan por una definición más precisa, evitando toda referencia al lucro; y (c) textos que incorporan alguna nota de originalidad no exenta de confusión al continuar utilizando la voz lucro acompañada de ciertos acotamientos del tipo "lucro con límites". Estas diferentes salidas de alguna manera son propias de un momento histórico caracterizado por las diferencias que aún persisten a la hora de definir los alcances y el sentido de la ESS. Lejos de un paradigma, la ESS sigue mostrando diversas interpretaciones desde el campo teórico e ideológico que naturalmente los textos legislativos recogen con sus propias limitaciones. Ese debate sobre los fines últimos de la economía solidaria se da con mayor fuerza en América Latina, lo que ha conducido a leyes de ESS con una mayor diversidad doctrinaria respecto a las leyes gestadas en Europa.
Bibliografía

ACI (1995): "Declaración sobre Identidad Cooperativa", en CUDECOOP (1996), Identidad y principios cooperativos, Montevideo, Nordan.

ACl - Américas (2009): "Ley Marco para las Cooperativas de América Latina" (en línea) ACl de las Américas. Disponible en https://www.aciamericas.coop/-Legislacion-Cooperativa-en-las-Americas (Consultado 10/4/2018).

ARGUDO PÉREZ (2007): “Las cooperativas sin ánimo de lucro: ¿Vuelta a los orígenes o respuesta a nuevas necesidades sociales?", GEZKI, 3, pp. 179-201.

BRUGAROLA, M. (1961): Doctrina y sistemática cooperativa, Santander, Sal Terrae.

CANO LÓPEZ, A. (2002): Teoría Jurídica de la Economía Social, Madrid, CES.

Comisión de Trabajo por Ley de ESS (2015): "Anteproyecto de Ley de ESS", Montevideo, INACOOP, paper.

CRACOGNA, D. (comp.) (2005): Régimen legal de las cooperativas en los países del MERCOSUR, Buenos Aires, RECM, Serie Jurídica.

FAJARDO GARCÍA, G. (2009): La Economía Social en las leyes, CIRIEC-España, Revista de economía pública, social y cooperativa, 66, pp. 5-35.

GUERRA, P. (2012): "Las legislaciones sobre economía social y solidaria", Documento de Trabajo no 4, Facultad de Derecho, Universidad de la República.

GUERRA, P y REYES, S. (2014): Economía Solidaria, Cooperativismo y Relaciones Laborales, Montevideo, FCU.

HAGEN, H. (2013): Orientaciones para la legislación cooperativa, Ginebra, OIT.

MONTERO, M. (2010): "La fiscalidad de las cooperativas sin ánimo de lucro" CIRIEC- España, 69, pp. 161-190.

OIT (1966): Recomendación 127 (en línea) ILO.ORG. Disponible en http:// www.ilo.org/dyn/normlex/es/f?p=NORMLEXPUB:55:0:::55:P55_ TYPE,P55_LANG,P55_DOCUMENT,P55_NODE:REC,es,R127,/Document (Consultado 11/4/2018).

OIT (2002): Recomendación 193, en RECM (2005), El rol de las cooperativas como parte integrante de la economía social en la cohesión social en América Latina y Europa, Buenos Aires, Intercoop.

ORECCHIA, F. (2004): "Impuestos nacionales", en D. Cracogna (comp.) (2005), Régimen legal de las cooperativas en los países del MERCOSUR, Buenos Aires, RECM, Serie Jurídica.

PÉREZ DE MENDIGUREN, J. C. y ETXEZARRETA, E. (2015): Sobre el concepto de economía social y solidaria: aproximaciones desde Europa y América Latina, Revista de Economía Mundial, 40, pp. 123-144.

RAZETO, L. (1991): Empresas de Trabajadores y Economía de Mercado, Santiago, PET.

Normas consultadas

Argentina (2013): Anteproyecto de Ley Nacional de Promoción de la Economía Popular, Social y Solidaria, en Dirección de Economía Social y Asociatividad (2015) "Digesto de la Economía Social" (en línea). Disponible en www.mendoza.gov.ar/wp-content/.../DIGESTO-DE-LAECONOMÍA-SOCIAL.pdf (Consultado 11/4/2018).

Brasil (1971): Lei no 5.764, en RECM (2005), Régimen Legal de las Cooperativas del MERCOSUR, Buenos Aires, Intercoop, 373 p.

Brasil (2012): Projeto lei Economía Solidaria 4685 (en línea), Cámara dos Deputados. Disponible en http://www.camara.gov.br/proposicoesWeb/ fichadetramitacao?idProposicao=559138 (Consultado 11/4/2018). 
Buenos Aires (2014): Ley de Promoción y Desarrollo de la Economía Social y Solidaria (en línea). Disponible en http://www.gob.gba.gov.ar/legislacion/legislacion/l-14650.html (Consultado 11/4/2018).

Chile (1978): Ley General de Cooperativas, decreto supremo 502 (en línea). Disponible en http://www.aplicacion.com.ar/legisc/chile/1.htm (Consultado 5/4/2018).

Colombia (1998): Ley 454/1998 (en línea). Disponible en: http://base.socioeco.org/docs/colombiamarcocomplementarioley454de1998.pdf (Consultado 20/1/2018)

Costa Rica (1982): Ley 6756 (en línea). Disponible en www.mag.go.cr/legislacion/1968/ley\%204179.pdf (Consultado 5/4/2018)

Ecuador (2011): Ley Orgánica de Economía Popular Solidaria (en línea) Disponible en http://www.seps.gob.ec/interna-npe?760 (Consultado 20/2/2018)

Entre Ríos (2012): Ley 10151 (en línea) Socioeco.org. Disponible en base. socioeco.org/docs/ley_10151_entre_rios.pdf (Consultado 11/4/2018).

España (2011): «Ley 5/2011 » sobre economía social (en línea) Disponible en http://noticias.juridicas.com/base_datos/Admin/l5-2011.html (Consultado 26/4/2018).

Francia (2014): Loi n 2014-856du 31 juillet 2014 relative à l'économiesociale et solidaire. JORF n0176 du 1 août 2014, page 12666, texte $n^{\circ} 2$. (EI línea) Disponible en: https://www.legifrance.gouv.fr/affichTexte.do ?cidTexte=JORFTEXT000029313296\&categorieLien=id (Consultado 20/2/2018)

Mendoza (2012): Ley de Promoción de la ESS 8435 (en línea), Socioeco.org. Disponible en http://www.socioeco.org/bdf_fiche-document-3731_ es.html (Consultado 12/4/2018)

México (2011): "Gaceta Parlamentaria", año XIV, número 3371-II, DF.

Portugal (1980): Decreto Lei 454/80 (en línea), DRE. Disponible en https:// dre.pt/web/guest/pesquisa/-/search/462212/details/maximized?pe rPage $=100 \&$ sort $=$ whenSearchable\&sortOrder $=$ ASC \& $q=$ Lei $+n . \% C 2 \%$ BA\%2010\%2F97 (Consultado 11/4/2018).

Portugal (2013): "Lei 30/2013" (en línea). Disponible en http://www.parlamento.pt/actividadeparlamentar/paginas/detalhediplomaaprovado. aspx?bid=17553 (Consultado 26/4/2018). http://www.parlamento.pt/actividadeparlamentar/paginas/detalhediplomaaprovado. aspx?bid $=17553$

República Dominicana (1964): Ley de Asociaciones Cooperativas 127/64 (en línea). Disponible en idecoop.gob.do/transparencia/.../ Ley_127_64_Asociaciones_Cooperativas.pdf (Consultado 5/4/2018)

Río de Janeiro (2008): Ley 5315 (en línea) FBES. Disponible en http://fbes. org.br/download/rj-lei-5315-nov-2008-pdf/ (Consultado 11/4/2018).

RS (2010): Lei 13.531 (en línea), Assembleia Legislativa. Disponible en www.al.rs.gov.br/filerepository/repLegis/arquivos/13.531.pdf (Consultado 11/4/2018). 